\title{
Expression and Significance of IL-6 and bFGF in Human Tongue Squamous Cell Carcinoma
}

\author{
Ju-Hua Hou1, Zheng-Bing He², Xiao-Ju Hou ${ }^{3}$, Yuan-Yue Liu' ${ }^{*}$, Wen-Jiang Zhang1, Juan Duan1 \\ ${ }^{1}$ Department of Pathology, Yiyang Medical University, Yiyang, China \\ ${ }^{2}$ Respiratory Medicine of Yiyang Central Hospital, Yiyang, China \\ ${ }^{3}$ School of Foreign Languages, Henan University of Technology, Zhengzhou, China \\ Email: ${ }^{*}$ liuyuanyue9019@163.com
}

How to cite this paper: Hou, J.-H., He, Z.-B., Hou, X.-J., Liu, Y.-Y., Zhang, W.-J. and Duan, J. (2017) Expression and Significance of IL-6 and bFGF in Human Tongue Squamous Cell Carcinoma. Journal of Cancer Therapy, 8, 210-215. https://doi.org/10.4236/jct.2017.82017

Received: January 22, 2017

Accepted: February 19, 2017

Published: February 22, 2017

Copyright @ 2017 by authors and Scientific Research Publishing Inc. This work is licensed under the Creative Commons Attribution International License (CC BY 4.0).

http://creativecommons.org/licenses/by/4.0/ (c) (i) Open Access

\begin{abstract}
Objective: To detect the expression and pathological significances of Interleukin-6 (IL-6) and basic fibroblast growth factor (bFGF) in tongue squamous cell carcinoma (TSCC). Methods: A tissue array was analyzed immunohistochemically. The expression levels of IL- 6 and bFGF in tissues were recorded semi-quantitatively. Results: The positive expression of IL-6 in normal, benign tumor, and carcinoma groups was $12.50 \% \pm 5.575 \%, 39.00 \% \pm 1.41 \%$, $77.26 \% \pm 17.07 \%$ respectively, and the expression among the three groups showed significant differences $(P<0.05)$. The expression of bFGF in benign tumor was lower than that in normal groups and squamous cell carcinoma. The positive expression was $6.50 \% \pm 2.12 \%, 23.75 \% \pm 4.79 \%, 42.33 \% \pm$ $29.89 \%$ respectively, and the expression among the three groups showed significant differences $(P<0.05)$. Furthermore, there were positive correlations between IL-6 and bFGF $(P<0.05)$. Conclusion: It indicates that combining immunohistochemical examination of IL- 6 and bFGF has an important reference value on the pathological diagnosis of tongue squamous cell carcinoma.
\end{abstract}

\section{Keywords}

Tongue Squamous Cell Carcinoma, Il-6, bFGF, Tissue Array

\section{Introduction}

Oral squamous cell carcinoma (OSCC) is a common disease of malignant tumors in digestive tract. Among all known tumors, its morbidity is the 8th, and its mortality 6th [1]; by the way, since the mortality of OSCC in China is the first around all over the world, and its prognosis is poor, and it's hard to effect a radical treatment, it's especially important to offer the prevention and treatment of the tumor [2]. The morbidity of tongue squamous cell carcinoma (TSCC) is at 
the top of OSCC, and is increasing year by year and shows the trend of younger; the rate of its early diagnosis is low [3]. Therefore, early detection, diagnosis, and treatment of TSCC are the future research direction. IL- 6 and bFGF, as such kind of small protein with wide biological activities, play an important role in interaction between cells and tumor formation, and have been the research focus in recent years [4]. However, there are few studies relating IL-6 and bFGF with TSCC. Based on this, the study is aiming at looking into the possible mechanism of the occurrence and development of TSCC, and providing a certain experimental and theoretical reference value for its early diagnosis and treatment.

\section{Materials and Methods}

\subsection{Materials}

The tongue tissue arrays were ordered from Guilin Fanpu Biotech, Inc. The batch number is TOC481 including 24 pairs of twin-granules. Each point sample is $1.5 \mathrm{~mm}$ in size, $4 \mu \mathrm{m}$ in thickness; they are arranged in $6 \times 8$. There are 24 samples including the normal tongue tissues and TSCC. All the tissues were coming from surgical excision, fixed 24 hours in the neutral formalin buffer liquid, and then processed with the method of unified standard. They are fixed in the imported American superfrost plus and the temperature is kept at $4^{\circ} \mathrm{C}$. Each point sample had been confirmed by pathological method. The number of the cases of malignant tumor, benign tumor, and normal tissue are 21,1 , and 2 respectively. The cases range from 23 to 77 years of age, and the median age is 54 years. Among them, 10 cases have high differentiation malignant tumor (G1), 8 cases have median differentiation malignant tumor (G2), and 3 cases have low differentiation malignant tumor (G3). According to cancer staging relying on the TNM system which is designed jointly by the Union for International Cancer Control and the American Joint Committee on Cancer, there are 2 cases in stage I , 18 cases in stage $I$, and 1 case in stage III.

\subsection{Reagent}

The rabbit anti-human IL-6 polyclonal antibodies were purchased from Abcam Company. The mouse anti-rat bFGF monoclonal antibodies came from the American Neomarker Company. The ready-to-use Max Vision TM immunohistochemical test kits (KIT-5030), the enzyme-substrate color development reagents and other reagents were purchased from Fuzhou Maixin Biotech. Co., Ltd. The working concentrations of both IL- 6 and bFGF are 1:200, and replacing primary antibodies, the PBS buffer is set as negative control.

\subsection{Using Immunohistochemical Staining and Finding Results}

Method: Immunohistochemical method (SP) was used, and diaminobenzidine (DAB) was used as reagent. According to the existing method [5] that the research group has already used, the judgment is as follows. 5 randomly selected high power fields $(10 \times 40)$ are observed in each slice, brown or dark drown granules indicating positive. Based on the percentage of positive cells to the total 
cells, the expression intensity can be classified into 4 levels: $(-)$ positive cells $<10 \%$; (+) positive cells 10\% - 30\%; (++) positive cells 31\% 50\%; (+++) positive cells $>50 \%$. Among them, $(-)$ and $(+)$ are low expression group, while $(++)$ and $(+++)$ are high expression group.

\subsection{Statistic analysis}

SPSS16.0 statistical analysis software was applied. All data were expressed as $\bar{x}$ $\pm s$; two samples were compared by chi-square test; the rank sum test was used among groups; Spearman rank correction test was used in factor correction analysis; $P<0.05$ was considered as statistically significant.

\section{Results}

After color developing, most granules were intact, and very few were deleted. However, because of the twin-granule settings, observation and statistical results were not affected.

\subsection{IL-6 Protein Expressions}

The expression of IL-6 was mainly in cell nucleus both in normal tongue tissue and benign tumor, and it was expressed in cytoplasm in squamous cell carcinoma. The positive expressions of IL-6 in normal, benign tumor, and carcinoma groups were $12.50 \% \pm 5.57 \%, 39.00 \% \pm 1.41 \%$, and $77.26 \% \pm 17.07 \%$ respectively; the expression rate in carcinoma groups was significantly higher than that in the other two, and the expressions among the three groups showed significant difference $(P<0.05)$. The expressions of IL-6 in high differentiation malignant tumor, median differentiation malignant tumor, and low differentiation malignant tumor were $86.30 \% \pm 3.53 \%, 66.90 \% \pm 11.49 \%$, and $75.00 \% \pm 10.80 \%$ respectively, and the difference was considered as no statistical significance. Moreover, the differences of the IL- 6 expressions in other groups (such as different ages, genders, lymphatic metastases, clinical stages, and so on) were also considered as no statistical significance $(P>0.05)$.

\section{2. bFGF Protein Expressions}

The positive expression of bFGF was mainly in cytoplasm in the normal tongue tissue. The expression of bFGF in benign tumor was lower than that in normal groups and squamous cell carcinoma. The positive expression were $6.50 \% \pm$ $2.12 \%, 23.75 \% \pm 4.79 \%, 42.33 \% \pm 29.89 \%$ respectively, and the expressions among the three groups showed significant difference $(P<0.05)$. The positive expressions in high differentiation tongue tissue, median differentiation tongue tissue, and low differentiation tongue tissue were $62.50 \% \pm 12.13 \%, 26.00 \% \pm$ $14.79 \%$, and $18.70 \% \pm 20.89 \%$ respectively; the expression rate in high differentiation groups was significantly higher than that in the other two. However, the differences of the bFGF expressions in other groups (such as different ages, genders, lymphatic metastases, clinical stages, and so on) were considered as no statistical significance $(P>0.05)$. 


\subsection{Correlations of Expression between IL- 6 and bFGF}

Through analyzing the correlations of expression between IL-6 and bFGF, it can be found that the expressions of both IL- 6 and bFGF were positive in tongue carcinoma tissue at 16 cases; at other 5 cases the expression of bFGF was negative, while the expression of IL- 6 was positive. Furthermore, there were significantly positive correlations between IL- 6 and bFGF $(P<0.05)$.

\section{Discussion}

The occurrence and development of OSCC is a complex process which involves multi-steps, multi-factors, polygenic-alteration, and multi-stages pathopoiesis [6]. As squamous cell carcinoma originates from epithelial cells, many domestic and overseas scholars have long focused on the study of mutated epithelial cells, and they also have made some major breakthroughs in the research area of oncogenes and tumor suppressor genes [7] [8]. However, recently, many articles in Nature, Science, and other magazines, have pointed out that the malignant transformation and the development process of epithelial cells are largely regulated by the reciprocal interactions between epithelial and mesenchymal cells; and under the microenvironment of the tumor-host interface, constituted by the complex biological signaling network, epithelial and mesenchymal cells play a key role in the process of epithelial proliferation, differentiation, invasion, and metastasis [9].

Cytokines are synthesized and secreted by immune cells (including lymphocytes and monocytes) and some non-immunocytes (such as vascular endothelial cells, neuroglial cells, and so on) are small, soluble proteins with the wide range of biological activities. Cytokines are the cores to communicate immune cells, and immune cells and non-immunocytes. Through interacting with cell-specific membrane receptors, cytokines can change the behaviors or properties of secretory cells and other cells. According to different functions, cytokine can be classified into interleukin (IL), colony stimulating factor (CSF), growth factor (GF), and so on, which most of the studies of oral cancer are concentrated on at present [10]. The IL series play an important role in the regulation of intercellular interaction, immunity adjustment, hematopoiesis, inflammatory process, and tumor formation.

IL-6 is a kind of protein with 26KD molecular weight, and composed of 184 amino acid molecules. It is a pleiotropic cytokine that can regulate a variety of cell functions including cell proliferation, cell differentiation, immune defense mechanism, hematopoiesis, etc. [11]. IL-6 correlates with genesis and progress of several kinds of tumors; it can influence tumor progress through intervening cells adhesion and activity, thrombosis, expression of tumor specific antigen, and tumor cells proliferation [12]. IL-6 can also regulate a variety of cell functions including cell proliferation, cell differentiation, immune defense mechanism, hematopoiesis, etc. In 2015, through observing the serum IL-6 level in patients with tongue cancer, Lotfi A etc. [13] concluded that the serum IL-6 level in patients with tongue cancer was significantly higher than that of the healthy 
controls. The study of this paper had obtained similar results from the histological level: the expression rate of IL-6 in carcinoma groups was significantly higher than that in the normal tongue tissue and benign tumor, and the expressions among the three groups showed significant difference; the expressions of IL-6 in high differentiation malignant tumor were higher than those in the median differentiation malignant tumor and low differentiation malignant tumor; and all these results indicated that IL-6 played an important role in the genesis and development of tumor.

bFGF is a kind of mitogenic cationic polypeptide and contains 155 amino acid molecules; $55 \%$ of the amino acid sequence of bFGF is similar with acid fibroblast growth factor (aFGF); the molecular weight of bFGF is $16-18.8 \mathrm{KD}$. Information available at present suggests that the biological functions of bFGF are extensive, and bFGF is very important in the promotion of angiopoiesis, wound healing and tissue repair, tissue regeneration, and the growth and development of nervous tissue [14] [15] [16]. The expression of bFGF in squamous cell carcinoma is significantly higher than that in normal groups and benign tumor and the expression rate in high differentiation groups is significantly higher than that in the other two. The study of the paper indicated that bFGF was in relation to the genesis and development of TSCC.

IL-6 and bFGF, as such kind of small protein with wide biological activities, play an important role in interaction between cells, and tumor formation, and have been the research focus in recent years. However, there are few researches relating IL- 6 and bFGF with TSCC. The study demonstrates that IL-6 and bFGF show the high expression in tumor, especially in malignant tumor, but the specific mechanism needs to be further explored. The study team will ascertain the possible mechanism of the occurrence and development of TSCC, in the hopes of providing some experimental and theoretical bases for its early diagnosis and treatment.

\section{Fund Projects}

The education department of Hunan Province: the expression and significance of IL-6 and bFGF under oral cancer micro environment (14C1123), the science and technology bureau of Yiyang: research on the effects of KLF6 on regulating epithelial mesenchymal transition in oral cancer cell through Notch pathways (the science and technology bureau of Yiyang [2016] 51th: 33).

\section{References}

[1] Weinberg, M.A. and Estefan, D.J. (2002) Assessing Oral Malignancies. American Family Physician, 65, 1379-1384.

[2] Mehrotra, R., Gupta, A., Singh, M., et al. (2006) Application of Cytology and Molecular Biology in Diagnosing Remalignant or Malignant Oral Lesions. Molecular Cancer, 5, 11. https://doi.org/10.1186/1476-4598-5-11

[3] Komolmalai, N., Chuachamsai, S., Tantiwipawin, S., et al. (2015) Ten-Year Analysis of Oral Cancer Focusing on Young People in Northern Thailand. Journal of Oral Science, 57, 327-334. https://doi.org/10.2334/josnusd.57.327 
[4] Di Bella, L.M., Alampi, R., Biundo, F., et al. (2017) Copper Chelation and Interleukin-6 Proinflammatory Cytokine Effects on Expression of Different Proteins Involved in Iron Metabolism in HepG2 Cell Line. BMC Biochemistry, 18, 1-11. https://doi.org/10.1186/s12858-017-0076-2

[5] Hou, J.-H., Liu, Y.-Y., Li, C., Deng, S.-H. and Liu, B.-Y. (2015) Effects of Buyang Huanwu Decoction on Cyclin D1 and Cdk2 of Post-Stroke Depression in Rats. Chinese Journal of Behavioral Medicine and Brain Science, 24, 680-683.

[6] Koo, K., Barrowman, R., McCullough, M., et al. (2013) Non-Smoking Non-Drinking Elderly Females: A Clinically Distinct Subgroup of Oral Squamous Cell Carcinoma Patients. International Journal of Oral \& Maxillofacial Surgery, 42, 929-933. https://doi.org/10.1016/j.ijom.2013.04.010

[7] Huang, J., Hou, J.-H., Wang, G.-H., et al. (2012) Effect of HMBA on Proliferation and Expression of KLF6 and Related Proteins in Human Tongue Carcinoma Tca8113 Cells. Chinese Journal of Pathophysiology, 28, 433-438.

[8] Franz, M., Spiegel, K., Umbreit, C., et al. (2009) Expression of Snail Is Associated with Myofibroblast Phenotype Development in Oral Squamous Cell Carcinoma. Histochemistry and Cell Biology, 131, 651-660. https://doi.org/10.1007/s00418-009-0559-3

[9] Goymer, P. (2008) Natural Selection: The Evolution of Cancer. Nature, 454, 1046 1048. https://doi.org/10.1038/4541046a

[10] Rossle, M., Weber, C.S., Zullig, L., et al. (2013) EGFR Expression and Copy Number Changes in Low T-Stage Oral Squamous Cell Carcinomas. Histopathology, 10, Article ID: 12175 . https://doi.org/10.1111/his.12175

[11] Migita, K., Izumi, Y., Jiuchi, Y., et al. (2014) Effects of Janus Kinase Inhibitor Tofacitinib on Circulating Serum Amyloid A and Interleukin-6 during Treatment for Rheumatoid Arthritis. Clinical \& Experimental Immunology, 175, 208-214. https://doi.org/10.1111/cei.12234

[12] Lai, X.-H., Yang, C.-X., Wang, H.-B., et al. (2014) Effects of Sufentanil Combined with Dezocine for Postoperative Analgesia on the Level of IL-2 and IL-6 and Blood Circulatory Micrometastasis of Laparoscopic Radical Operation on Gastric Cancer Patients. Guangdong Medical Journal, 35, 2540-2542.

[13] Lotfi, A., Shahidi, N., Bayazian, G., et al. (2015) Serum Level of Interleukin-6 in Patients with Oral Tongue Squamous Cell Carcinoma. Iranian Journal of Otorhinolaryngology, 27, 207-211.

[14] Podergajs, N., Brekka, N., Radlwimmer, B., et al. (2013) Expansive Growth of Two Glioblastoma Stem-Like Cell Lines Is Mediated by bFGF and Not by EGF. Radiology and Oncology, 47, 330-337.

[15] Ma, J.-F., Yang, C.-Y., Qiu, H.-H., et al. (2013) Expression and Significance of Basic Fibroblast Growth Factor and Bcl-2 in Ovarian Malignant Epithelial Tumor. Guangdong Medical Journal, 34, 228-230.

[16] Nayak, S., Goel, M.M., Makker, A., et al. (2015) Fibroblast Growth Factor (FGF-2) and Its Receptors FGFR-2 and FGFR-3 May Be Putative Biomarkers of Malignant Transformation of Potentially Malignant Oral Lesions into Oral Squamous Cell Carcinoma. PLoS ONE, 10, 1-19. https://doi.org/10.1371/journal.pone.0138801 
Submit or recommend next manuscript to SCIRP and we will provide best service for you:

Accepting pre-submission inquiries through Email, Facebook, LinkedIn, Twitter, etc. A wide selection of journals (inclusive of 9 subjects, more than 200 journals)

Providing 24-hour high-quality service

User-friendly online submission system

Fair and swift peer-review system

Efficient typesetting and proofreading procedure

Display of the result of downloads and visits, as well as the number of cited articles Maximum dissemination of your research work

Submit your manuscript at: http://papersubmission.scirp.org/

Or contact jet@scirp.org 